\title{
Quaternized cashew gum: An anti-staphylococcal and biocompatible cationic polymer for biotechnological applications
}

\author{
Patrick V. Quelemes ${ }^{\mathrm{a}}$, Alyne R. de Araújo ${ }^{\mathrm{a}}$, Alexandra Plácido ${ }^{\mathrm{b}}$, Cristina Delerue-Matos ${ }^{\mathrm{b}}$, \\ Jeanny S. Maciel ${ }^{\mathrm{c}}$, Lucinda J. Bessa $^{\mathrm{d}}$, Alicia S. Ombredane ${ }^{\mathrm{e}}$, Graziella A. Joanitti $^{\mathrm{e}}$, \\ Maria José dos S. Soares ${ }^{\mathrm{f}}$, Peter Eaton ${ }^{\mathrm{a}, \mathrm{d}}$, Durcilene A. da Silva ${ }^{\mathrm{a}}$, \\ José Roberto S.A. Leite ${ }^{\mathrm{a}, \mathrm{d}, \mathrm{g}, *}$
}

\footnotetext{
a Núcleo de Pesquisa em Biodiversidade e Biotecnologia, Biotec, Universidade Federal do Piauí, UFPI, 64202020 Parnaíba, PI, Brazil

${ }^{\mathrm{b}}$ REQUIMTE/LAQV, Instituto Superior de Engenharia do Porto, Instituto Politécnico do Porto, Rua Dr. António Bernardino de Almeida, $431,4200-072$ Porto, Portugal

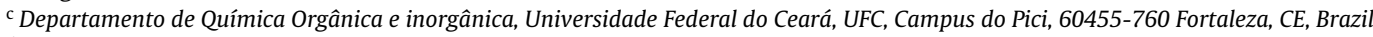

d UCIBIO, REQUIMTE, Departamento de Química e Bioquímica, Faculdade de Ciências, Universidade do Porto, 4169-007 Porto, Portugal

e Laboratório de Nanobiotecnologia, Instituto de Biologia, Universidade de Brasília, UnB, 70910-900 Brasília, Distrito Federal, DF, Brazil

${ }^{\mathrm{f}}$ Departmento de Morfofisiologia Veterinária, Universidade Federal do Paiuí, 64049550 Teresina, PI, Brazil

g Área de Morfologia, Faculdade de Medicina, FM, Universidade de Brasília, UnB, Campus Universitário Darcy Ribeiro, Asa Norte, Brasília, Distrito Federal,

DF 70910-900, Brazil
}

\author{
A B S T R A C T
}

\begin{abstract}
Chemical modifications to cashew gum (CG) structure have been previously reported to obtain new physicochemical characteristics, however until now there were no reports of modifications by introduction of new functional groups to add cationic character. This study presents a quaternization route for CG using a quaternary ammonium reagent. The chemical features of the quaternized cashew gum derivatives (QCG) were analyzed by: FTIR, elemental analysis, degree of substitution, Zeta potential, ${ }^{1} \mathrm{H}$ NMR and ${ }^{1} \mathrm{H}^{13} \mathrm{C}$ correlation (HSQC). QCG were evaluated for their anti-staphylococcal activity by determining minimum inhibitory and bactericidal concentrations against pathogenic Staphylococcus spp. and by imaging using atomic force microscopy. Moreover, the mammalian cell biocompatibility were also assessed through hemolytic and cell toxicity assays. QCG presented promising antimicrobial activity against methicillin-resistant $S$. aureus and biocompatibility on tested cells. These results show that QCG could be a promising tool in the development of biomaterials with an anti-septic action.
\end{abstract}

Keywords:

Cashew gum

Quaternization

Antibacterial

Staphylococcus spp.

Biocompatibility

\section{Introduction}

The exudate from the Anacardium occidentale L. tree stem, commonly known as cashew gum (CG), is a natural product extracted in a low cost and sustainable manner. The study of the properties

\footnotetext{
* Corresponding author at: Área de Morfologia, Faculdade de Medicina, FM, Universidade de Brasília, UnB, Campus Universitário Darcy Ribeiro, Asa Norte, Brasília Distrito Federal, DF, Brasil 70910-900.

E-mail addresses: jrsaleite@gmail.com, jrleite@pq.cnpq.br (J.R.S.A. Leite).
}

of CG has contributed towards the added value in the production of this commercialized plant (Cunha, Paula \& Feitosa, 2009; Lima, Lima, de Salis, \& Moreira, 2002; Ribeiro et al., 2016). This gum is an anionic heteropolysaccharide with the capacity to form viscous and emulsifying suspensions that may be used in the food and pharmaceutical industries (De Paula, Healthy \& Budd, 1998; Gowthamarajan, Kumar, Gaikwad, \& Suresh, 2011; Kumar, Patil, Patil, \& Paschapur, 2009; Kumar, Moin, Shruthi, Ahmed, \& Shivakumar, 2012; Porto \& Cristianini, 2014). Moreover, CG has promise of applications in nanobiotechnology (Araruna et al., 2013; 
Dias et al., 2016; Oliveira, Paula \& de Paula, 2014; Quelemes et al., 2013; Silva et al., 2009).

CG is composed mainly of $\beta$-D-galactose (72\%), followed by $\alpha$ D-glucose (14\%), arabinose (4.6\%), rhamnose (3.2\%) and glucuronic acid (4.6\%). Its main chain contains galactose units joined by links of the type $\beta(1 \rightarrow 3)$, and in the side chain, $\beta(1 \rightarrow 6)$ (De Paula et al., 1998).

Studies regarding the biological activities of CG have also been reported, revealing: weak antimicrobial activity (Campos et al., 2012; Torquato et al., 2004), healing effect (Schirato et al., 2006), immuno-modulation capacity (Yamassaki et al., 2015), as well as antidiarrheal (Araújo, Costa et al., 2015) and gastroprotective properties (Carvalho et al., 2015).

Chemical modifications in the structure of this polymer by introduction of new functional groups by using: carboxymethylation (Silva et al., 2004); oxidation (Cunha, Maciel, Sierakowski, de Paula, \& Feitosa, 2007), sulphation (Neto, Maciel, Cunha, de Paula, \& Feitosa, 2011) and acetylation (Pitombeira et al., 2015) have been carried out in order to obtain new physicochemical characteristics. However, no reactions of polymer functionalization have been carried out yet in order to make it cationic.

Konjac glucomannan (Yu, Huang, Ying, \& Xiao, 2007), guar gum (Banerjee et al., 2013; Pal, Mal \&, Singh, 2007), cellulose (Song, Sun, Zhang, Zhou, \& Zhang, 2008), tamarind kernel (Pal, Ghosh, Sen, Jha, \& Singh, 2009), chitosan (Sajomsang, Gonil, \& Tantayanon, 2009; Singh, Pal, \& Ali, 2014), dextran and pullulan (Nichifor, Stanciu, \& Simionescu, 2010), starch (Singh et al., 2014; Wang \& Xie, 2010), gellan gum (Novac, Lisa, Profire, Tuchilus, \& Popa, 2014), amylose, amylopectin and glycogen (Singh et al., 2014) are examples of polysaccharides obtained from natural sources that have been modified by quaternization.

In this process, cationic moieties are introduced in the polymer structure mainly using quaternary ammonium reagents such as $\mathrm{N}$-(3-chloro-2-hydrohypropyl) trimethylammonium chloride CHPTAC (Singh et al., 2014). Quaternary ammonium compounds contain a positively charged "head" bearing four bonds and tend to be water-soluble and are quite stable, yielding a wide range of applications (Jennings, Minbiole, \& Wuest, 2015).

Quaternized derivatives acquire new or improved properties such as: high water solubility (Sajomsang et al., 2009), flocculant action (Pal et al., 2007; Pal et al., 2009; Singh et al., 2014), gene carrier ability (Song et al., 2008) and antimicrobial activity (Nichifor et al., 2010; Yu et al., 2007).

In this context, cationic quaternized cashew gum derivatives (QCG) resulting from a quaternization reaction could have new physicochemical features and biological properties, especially antibacterial activity, due to likelihood of stronger electrostatic interaction toward the negatively charged bacterial cell surface (Jennings et al., 2015). This effect associated with the maintenance of biocompatibility are prerequisites of a candidate agent to be used, for example, as an excipient in topical formulations or integrated to biotechnological devices as nanocomposites and biomaterials for use in antisepsis and healing procedures (Hirsch et al., 2010; Piraino \& Selimovic, 2015).

Thus, cationic agents may contribute to the prevention and treatment of skin infections, particularly those caused by bacteria of the Staphylococcus genus. The bacterium S. aureus, for instance, is an opportunistic pathogen related to severe skin, soft tissues and nosocomial infections, mainly due its ability to acquire resistance to antibiotics (DeLeo \& Chambers, 2009; Yu et al., 2015), thus new agents to combat it are urgently needed (Pasberg-Gauhl, 2014).

This study presents a chemical modification route for CG using a quaternary ammonium reagent, evaluates the effect of its quaternized derivatives on pathogenic bacteria of the Staphylococcus genus and assess their biocompatibility.

\section{Material and methods}

\subsection{Quaternization reaction}

\subsubsection{Materials and reagents}

(3-Chloro-2-hydroxypropyl)trimethylammonium chloride solution - CHPTAC (60 wt.\% in $\mathrm{H}_{2} \mathrm{O}$ ) (Sigma-Aldrich); sodium hydroxide (Neon); hydrochloric acid (Vetec) and acetone (Vetec) were analytical grade reagents used in the CG quaternization process. Dialysis membrane was obtained from Sigma-Aldrich. CG was isolated and purified by following the method of Dias et al. (2016).

\subsubsection{Chemical reaction}

A previously described method (Pal et al., 2007) was used to carry out quaternization through an $\mathrm{S}_{\mathrm{N}}^{2}$ pathway. An aqueous solution of the previously isolated and purified CG was prepared by dissolving $1 \mathrm{~g}$ of this polysaccharide in $1.5 \mathrm{~mL}$ of water at room temperature by constant stirring for about $30 \mathrm{~min}$, when a homogeneous paste was formed. Then, CHPTAC (60 wt.\% in $\mathrm{H}_{2} \mathrm{O}$ ) and aqueous solution of $5 \mathrm{M} \mathrm{NaOH}$ were added to the $\mathrm{CG}$ solution, with a subsequent stirring for more $30 \mathrm{~min}$. For the quaternization reaction, the molar ratios of CG/CHPTAC/NaOH were: $1 / 2 / 2$ for QCG -1 ; $1 / 4 / 4$ for QCG-2; and 1/6/6 for QCG-3.The reaction was then continued for $14 \mathrm{~h}$ in a water bath at $50^{\circ} \mathrm{C}$. Then, $1 \mathrm{M} \mathrm{HCl}$ was added to lower the $\mathrm{pH}$ to 5.5 in order to stop the quaternization process. The modified polymer solution was precipitated by adding an excess of acetone P.A, followed by dialysis and then lyophilization.

\subsubsection{Chemical characterization}

Infrared measurements were performed on a Fourier transform infrared (FTIR) spectrophotometer (FT-IR System Spectrum BX, Perkin Elmer) using the attenuated total reflection (ATR) technique and a spectral range from 4000 to $500 \mathrm{~cm}^{-1}$. Elemental analysis for carbon, hydrogen and nitrogen composition was performed using CHNS analyzer Perkin Elmer 2400 series, with thermal conductivity detector. The degree of substitution (DS) of the QCG derivatives was recorded from the nitrogen percentage using Eq. (1) (Banerjee et al., 2013; Huang, Yu, \& Xiao, 2007). DS was defined as the number of hydroxyl groups substituted per sugar unit of CG, where $\mathrm{N}$ is the nitrogen amount (\%) determined by elemental analysis (discounting the negligible amount present in CG).

$\mathrm{DS}=\frac{162.2 \times \mathrm{N}(\%)}{1400-151.5 \times \mathrm{N}(\%)}$

Solubility tests were carried out by stirring the gums in the deionized water for $5 \mathrm{~min}$ at a concentration of $10 \mathrm{mg} / \mathrm{mL}$, which was followed by visual observation. The solubility was defined as fully dissolved (+++), swollen $( \pm)$, and insoluble $(-)$.

Zeta potential $(\zeta)$ measurements were analyzed in a Malvern Zetasizer Nano, Model ZS 3600. Each sample, at a concentration of $10 \mathrm{mg} / \mathrm{mL}$, was measured 3 times for two replicate samples at a constant temperature of $25^{\circ} \mathrm{C}$.

1D $\left({ }^{1} \mathrm{H}\right)$ and $2 \mathrm{D}\left({ }^{1} \mathrm{H}-{ }^{13} \mathrm{C}\right.$ heteronuclear single-quantum correlation, HSQC) NMR spectra of CG and QCG-3 were measured on a Bruker AVANCE $500 \mathrm{MHz}$ at $300 \mathrm{~K}$ and using $\mathrm{D}_{2} \mathrm{O}$ as a solvent content DSS (4,4-dimethyl-4-silapentane-1-sulfonic acid) as internal standard $(0.01 \% \mathrm{w} / \mathrm{v}) .{ }^{1} \mathrm{H}_{-}{ }^{13} \mathrm{C}$ correlation (HSQC) was performed with pulse sequence currently used.

\subsection{Anti-staphylococcal activity tests}

\subsubsection{Bacterial growth and culture conditions}

Eleven strains of belonging to the Staphylococcus genus were selected for this study: eight $S$. aureus, three methicillinsensitive (MSSA) and five methicillin-resistant (MRSA); and three $S$. 
epidermidis, one methicillin-sensitive (MSSE) and two methicillinresistant (MRSE). Bacteria were stored in glycerol-saline solution at $-80^{\circ} \mathrm{C}$ and, for the experiments, were reactivated in MuellerHinton broth (HIMEDIA) and incubated at $37^{\circ} \mathrm{C}$ for $24 \mathrm{~h}$. From the broth, they were cultured in Mueller-Hinton agar (HIMEDIA) in the same conditions. Afterwards, isolated colonies were selected to prepare a suspension in sterile saline solution $(\mathrm{NaCl}-0.9 \% \mathrm{w} / \mathrm{v})$ of bacterial strains with a turbidity equivalent to a $0.5 \mathrm{McF}$ arland standard $\left(1-2 \times 10^{8} \mathrm{CFU} / \mathrm{mL}\right)$. This suspension was further diluted in order to obtain the desired concentration for the experiment described below.

\subsubsection{Minimum inhibitory and bactericidal concentrations (MIC and $M B C$ )}

MIC was determined using 96-well microdilution plates where all strains (concentration of $5 \times 10^{5} \mathrm{CFU} / \mathrm{mL}$ ) (CLSI, 2012) were exposed to a two-fold dilution series of the CG and QCG derivatives with concentrations ranging from 7.81 to $1000 \mu \mathrm{g} / \mathrm{mL}$ in Mueller-Hinton broth (HIMEDIA). Oxacillin and vancomycin were used as antibiotic standard controls. MIC was defined as the lowest concentration of agent that inhibited the bacterial visual growth. For the MBC determination, aliquots $(10 \mu \mathrm{L})$ from all wells with concentrations equal or higher to the MIC were sub-cultured on Mueller-Hinton agar (HIMEDIA). MBC was defined as the lowest concentration that enabled no growth on the agar (99.9\% kill). In both tests, the microorganisms were incubated for $24 \mathrm{~h}$ in temperature of $37^{\circ} \mathrm{C}$, at aerobic conditions. These assays were performed in triplicate.

\subsubsection{Atomic force microscopy (AFM) analysis}

MIC and MBC values of QCG-3 on S. aureus ATCC 29123 were determined as described in Section 2.2.2, with some modifications. Briefly, the concentrations of the QCG-3 ranged from 250 to $1000 \mu \mathrm{g} / \mathrm{mL}$ and a more concentrated inoculum was used $\left(1 \times 10^{8} \mathrm{CFU} / \mathrm{mL}\right)$ in order to facilitate observation by AFM, as previously described (Araújo, Quelemes et al., 2015). After incubation for $24 \mathrm{~h}, 20 \mu \mathrm{L}$ of the culture media containing the MIC and MBCtreated or untreated bacteria were deposited onto a clean glass surface followed by drying in ambient temperature for $15 \mathrm{~min}$. The samples were then gently rinsed twice with $1 \mathrm{~mL}$ of deionized water to remove salt crystals and dried again under the same conditions, before AFM analysis. All samples were prepared at the same time, exposed to the same conditions, and examined within $8 \mathrm{~h}$ of deposition. AFM was carried out with TT-AFM microscope from AFM Workshop (USA). The analysis of the QCG-3 effect on S. aureus cells was performed in vibrating mode, using NSG10 cantilevers (NTMDT) with a resonant frequency of approximately $280 \mathrm{kHz}$. Images were analyzed using Gwyddion software 2.45. Multiple areas of each sample were examined and selected representative images are shown.

The size (height) of treated and untreated bacteria was measured using the package Gwyddion 2.45. Statistical analysis of the results was carried out with GraphPad Prism 7.01 software. To compare the size of bacteria, the t-test was applied and the results expressed as the mean $\pm S D$, with " $n$ " ranged between 10 and 17 samples. A P $<0.001$ was considered statistically significant.

\subsection{Biocompatibility assessment}

\subsubsection{Hemolysis assay}

The hemolytic activity of the CG and QCG derivatives were tested using human red blood cells (RBCs), collected in EDTA $(1.8 \mathrm{mg} / \mathrm{mL})$, washed three times, and re-suspended with sterile saline solution (0.9\%), as previously described (Sahariah et al., 2015). CG and QCG derivatives were tested on RBCs at different concentrations, from 62.5 to $1000 \mu \mathrm{g} / \mathrm{mL}$. Triton-X (0.1\% v/v) and saline solution were used as positive and negative hemolysis controls, respectively. The mixtures were incubated for $1 \mathrm{~h}$ at $37^{\circ} \mathrm{C}$ and centrifuged at $10,000 \mathrm{~g}$ for $1 \mathrm{~min}$. The value of absorbance of the supernatant (A) was measured at $492 \mathrm{~nm}$. The hemolysis percentage (HP) was calculated as follows:

$\mathrm{HP}=\frac{\left(\mathrm{A}_{\text {Gum }}-\mathrm{A}_{\text {Saline }}\right)}{\left(\mathrm{A}_{\text {Triton }}-\mathrm{A}_{\text {Saline }}\right)} \times 100 \%$

\subsubsection{Cytotoxicity assay}

The human keratinocyte cell line HaCAT and murine fibroblast cell line NIH-3T3 were maintained in culture flasks at $37^{\circ} \mathrm{C}$ in $5 \%$ $\mathrm{CO}_{2}$ in Dulbecco's Modified Eagle Medium with $100 \mathrm{UI} / \mathrm{mL}$ penicillin and $100 \mu \mathrm{g} / \mathrm{mL}$ streptomycin supplemented with $10 \%(\mathrm{v} / \mathrm{v})$ heat inactivated fetal bovine serum (Life Technologies). For determining the cytotoxicity, cells were seeded on 96-well plates at a density of $3 \times 10^{3}$ cells per well in culture medium overnight at $37{ }^{\circ} \mathrm{C}$ in $5 \% \mathrm{CO}_{2}$. Then, the medium was changed and cells were incubated with different concentrations of CG and QCG derivatives (from 62.5 to $1000 \mu \mathrm{g} / \mathrm{mL}$ ). Sterile ultrapure water was used as control. The experiment was performed in triplicate and cell viability was determined by a 3,4,5-dimethylthiazol-2,5 biphenyl tetrazolium bromide (MTT- Life Technologies) assay (Araújo, Quelemes et al., 2015). After $24 \mathrm{~h}$ of gums exposition, $15 \mu \mathrm{L}$ of MTT solution $(5 \mathrm{mg} / \mathrm{mL}$ in PBS) were added to each well and incubated for more $2 \mathrm{~h}$ at $37^{\circ} \mathrm{C}$ in $5 \% \mathrm{CO}_{2}$, then the culture media was removed and $100 \mu \mathrm{L}$ of dimethyl sulfoxide (DMSO) were added. The absorbance was monitored using a spectrophotometer with a microplate reader at a wavelength of $595 \mathrm{~nm}$. The results are shown as\% of cell viability in relation to the non-treated cells in the water control.

\section{Results and discussion}

\subsection{Quaternization reaction and characterization}

In order to produce cationic cashew gum derivatives, a quaternization process was carried out using CHPTAC as etherifying agent under the catalytic action of $5 \mathrm{M} \mathrm{NaOH}$. This reaction is characterized by nucleophilic substitution in hydroxyl group of monosaccharide unit by quaternary ammonium reagent (Fig. 1). This reaction can be explained as follows (according to Yu et al., 2007): $\mathrm{NaOH}$ reacts with hydroxyl groups of CG to yield alkoxide groups; epoxide groups are also produced from CHPTAC by applying a stoichiometric amount of base; QCG is then formed through reaction between the CG alkoxide with epoxide or CHPTAC. Substitution of CG groups is likely to occur in C-6 of gum structure (Ribeiro et al., 2016). Through this reaction, after dialysis and lyophilization, it was obtained around $75 \%$ of yield.

The chemical characterization was carried out to confirm the polymer chemical modification. Fig. 2 shows the FTIR spectra of the CG and its quaternized derivatives. In the spectra, it is possible to observe characteristic bands of $\mathrm{O}-\mathrm{H}\left(3300 \mathrm{~cm}^{-1}\right)$, a stretching vibration mode of $\mathrm{C}-\mathrm{H}\left(2920 \mathrm{~cm}^{-1}\right)$ and a group of bands at 1040 , 1082 and $1122 \mathrm{~cm}^{-1}$ assigned to $\mathrm{C}-\mathrm{O}-\mathrm{C}$ from glycosidic bonds and $\mathrm{O}-\mathrm{H}$ bending of alcohols (Pitombeira et al., 2015). Owing to the quaternization reaction, the most striking difference between the CG and its derivatives was a peak obtained at $1478 \mathrm{~cm}^{-1}$, which corresponds to $\mathrm{C}-\mathrm{H}$ symmetric bending of methyl groups of the quaternary ammonium substituents (Novac et al., 2014; Yu et al., 2007), moreover the presence of a slight band at 1407 due to the presence of stretching vibration mode C-N (Pal et al., 2007; Song et al., 2008) can also be noticed.

Elemental analysis for CG and QCG derivatives are shown in Table 1 . The presence of a high percentage of nitrogen in modified gums confirms that the CHPTAC was incorporated into the polymer 


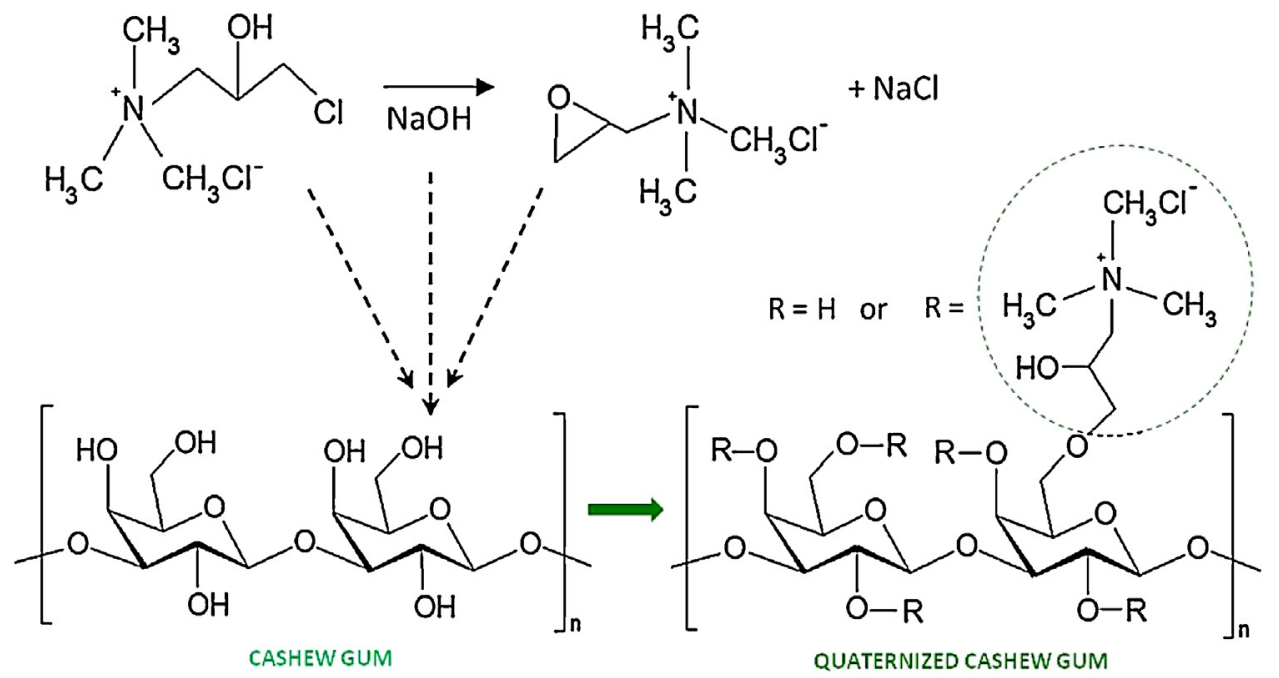

Fig. 1. CG quaternization reaction simplified scheme.

Table 1

Obtained results from the quaternization reaction and chemical features of CG and its quaternized derivatives.

\begin{tabular}{|c|c|c|c|c|c|c|c|}
\hline \multirow[t]{2}{*}{ Sample } & \multirow[t]{2}{*}{ Yield(\%) } & \multicolumn{3}{|c|}{ Elemental Analysis (\%) } & \multirow[t]{2}{*}{ DS } & \multirow[t]{2}{*}{ Zeta Potential $(\zeta) \mathrm{mV}$} & \multirow[t]{2}{*}{ Solubility } \\
\hline & & $\mathrm{C}$ & $\mathrm{H}$ & $\mathrm{N}$ & & & \\
\hline CG & - & 37.9 & 6.15 & 0.14 & - & -3.4 & \pm \\
\hline QCG-1 & 71 & 41.1 & 7.32 & 2.76 & 0.42 & +38.7 & +++ \\
\hline QCG-2 & 79 & 41.4 & 8.78 & 3.74 & 0.68 & +39.7 & +++ \\
\hline QCG-3 & 75 & 41.1 & 8.32 & 3.90 & 0.73 & +40.4 & +++ \\
\hline
\end{tabular}

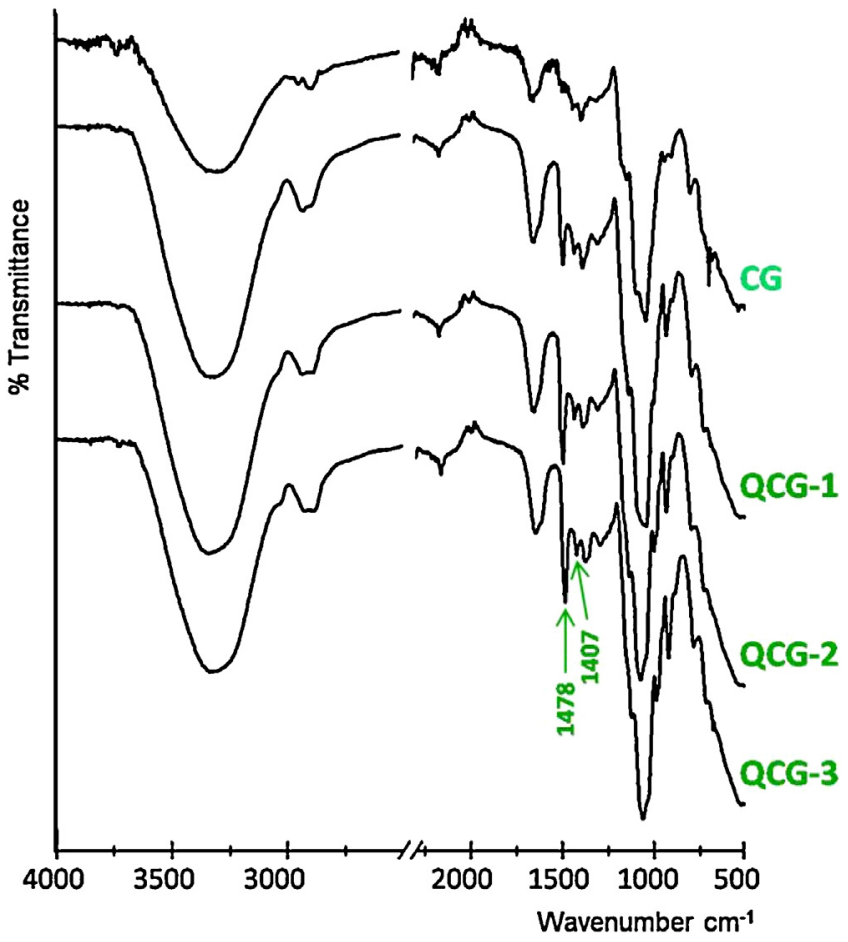

Fig. 2. FTIR spectra of the CG and QCG derivatives. Arrows indicate bands obtained due to the chemical modification.

backbone (Banerjee et al., 2013), highlighting an increase in the percentage of nitrogen due to the increase of the amounts of CHPTAC and $\mathrm{NaOH}$ added to the reaction (Pal et al., 2007). This effect is concomitant to an increasing degree of substitution (Yu et al., 2007). Slight amount of nitrogen $(0.14 \%)$ in the CG may correspond to the presence of traces of proteins (De Paula \& Rodrigues, 1995).
The modification can also be confirmed due to the change it causes in the water solubility of the gum (Table 1). This effect has been reported in the particular case of quaternized chitosan (Sajomsang et al., 2009). The data obtained from Zeta potential show a change in the charge of the polymer solution (Table 1 ), once the CG has a slightly negative potential and all derivatives showed strong positive values, which are typical of cationic polyelectrolyte compounds.

Fig. 3A and B shows the 2D heteronuclear ${ }^{1} \mathrm{H}-{ }^{13} \mathrm{C}$ HSQC of CG and QCG-3, respectively. In CG and QCG-3 derivative, the signals at $\delta 1.25 / 17.1$ that correspond to the methyl protons of the Rha unit are observed. This may indicate the presence of branched structures preserved. Distinguishable correlations referred to $\mathrm{C}_{6} / \mathrm{H}_{6}$ at $\delta 3.77 / 61.63$ (Fig. 3A) and $\delta 3.89 / 60.83$ (Fig. 3B) were noticed. In the QCG-3 derivative (Fig. 3B), the following new correlations were observed (the letters are associated with the chemical structure inserted in the figure): $\delta 3.87 / 74.2$ attributed to proton and carbon "a"; $\delta 4.42 / 65.3$ attributed to "b"; $\delta 3.6 / 68.1$ attributed to "c" and $\delta 3.22 / 54.9$ attributed to the N,N,N - trimethyl of "d". It was also highlighted a strong signal at $\delta 3.22$ observed by ${ }^{1} \mathrm{H}$ NMR.

Yu et al. (2007) reported the ${ }^{13} \mathrm{C}$ NMR spectra of quaternized konjac glucomannan (QKGM) and CHPTAC. The signals for carbons "a" was attributed at $\delta 73.4$ in QKGM. The signals observed for carbons "b", "c" and "d" in the CHTPAC were similar that observed in QKGM, in $\delta 65.4,68.3$ and 54.6, respectively. These signals were also clearly observed in the QCG-3 derivative (Fig. 3B).

\subsection{Anti-staphylococcal activity}

Reference and cataloged clinical pathogenic strains with recognized virulence were selected for this study. To evaluate the antimicrobial activity of CG and its derivatives towards Staphylococcus spp. strains, the MIC and MBC were determined and the results are shown in Table 2. The natural CG did not inhibit the bacterial growth within the range of concentrations tested. A previous 


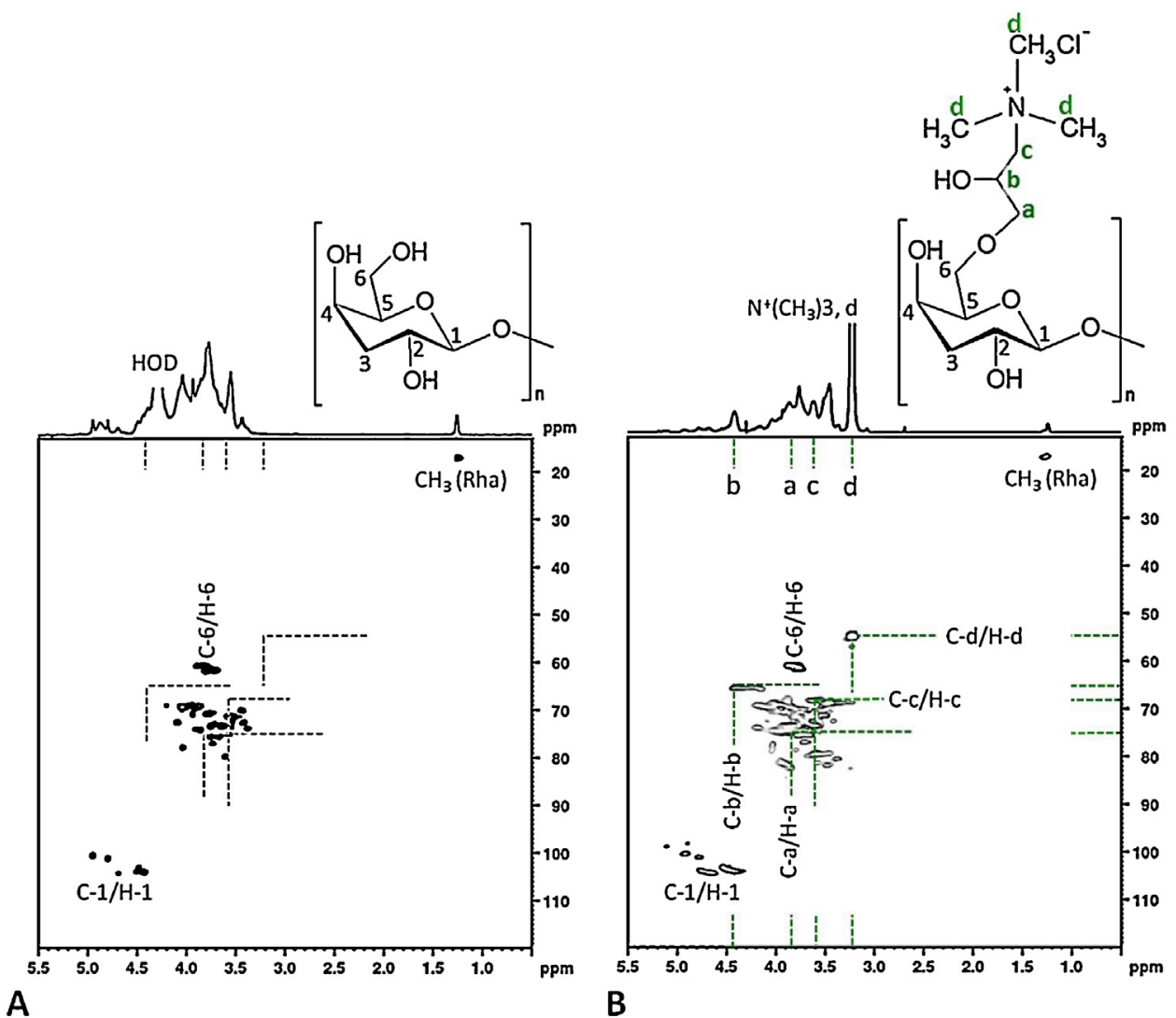

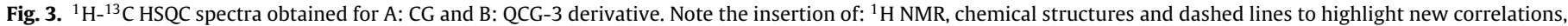
absent in $\mathrm{A}$ and present in $\mathrm{B}$ ).

Table 2

Minimum inhibitory concentrations (MIC) and minimum bactericidal concentrations (MBC) of QCG derivatives ( $\mu \mathrm{g} / \mathrm{mL}$ ) against Staphylococcus spp.

\begin{tabular}{|c|c|c|c|c|c|c|c|}
\hline \multirow[t]{2}{*}{ Bacterial strain } & \multicolumn{2}{|l|}{ QCG-1 } & \multicolumn{2}{|c|}{ QCG-2 } & \multicolumn{2}{|l|}{ QCG-3 } & \multirow{2}{*}{$\begin{array}{l}\text { Control } \\
\text { MIC }\end{array}$} \\
\hline & MIC & $\mathrm{MBC}$ & MIC & MBC & MIC & $\mathrm{MBC}$ & \\
\hline S. aureus ATCC 29213 (MSSA) & 1000 & 1000 & 250 & 250 & 125 & 125 & $<0.25^{\mathrm{a}}$ \\
\hline S. aureus ATCC 25923 & 1000 & 1000 & 125 & 125 & 125 & 125 & $<0.25^{\mathrm{a}}$ \\
\hline S. aureus MS52 (MSSA) Isolated from skin burn. & 1000 & 1000 & 250 & 500 & 125 & 250 & $0.25^{\mathrm{a}}$ \\
\hline S. aureus ATCC 43300 (MRSA) & 500 & 1000 & 62.5 & 62.5 & 62.5 & 62.5 & $0.5^{\mathrm{b}}$ \\
\hline S. aureus - Col (MRSA) & 1000 & 1000 & 125 & 125 & 62.5 & 125 & $0.5^{\mathrm{b}}$ \\
\hline S. aureus MR17 (MRSA) Isolated from surgical wound. & 500 & 1000 & 62.5 & 125 & 31.25 & 62.5 & $0.5^{\mathrm{b}}$ \\
\hline S. aureus MR359 (MRSA) Isolated from surgical wound. & 1000 & 1000 & 125 & 250 & 125 & 125 & $0.5^{\mathrm{b}}$ \\
\hline S. aureus MR0405 (MRSA) Isolated from nasal secretion. & 1000 & $>1000$ & 125 & 250 & 62.5 & 125 & $0.5^{\mathrm{b}}$ \\
\hline S. epidermidis ATCC 12228 (MSSE) & 62.5 & 1000 & 31.25 & 250 & 31.25 & 250 & $0.25^{\mathrm{a}}$ \\
\hline S. epidermidis MR111 (MRSE)Isolated from blood culture. & 1000 & 1000 & 125 & 500 & 125 & 250 & $1.0^{\mathrm{b}}$ \\
\hline S. epidermidis 70D (MRSE) Isolated from blood culture. & 1000 & 1000 & 125 & 250 & 125 & 125 & $1.0^{\mathrm{b}}$ \\
\hline
\end{tabular}

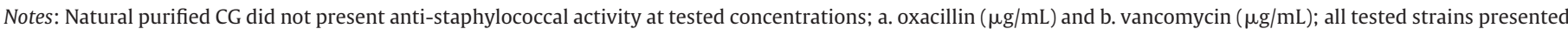
the predicted susceptibility to the standard antibiotics recommended by CLSI.

study reported for the CG a MIC value of $30 \mathrm{mg} / \mathrm{mL}$ against $S$. aureus (Campos et al., 2012).

On the other hand, all QCG tested presented antimicrobial activity against the selected bacteria (Table 2). S. aureus - Col, the first documented clinical methicillin-resistant isolate (Jevons, 1961), for instance, was inhibited by QCG-1 at a concentration of $500 \mu \mathrm{g} / \mathrm{mL}$. The other two derivatives showed even more marked activity, with MIC of $125 \mu \mathrm{g} / \mathrm{mL}$ for QCG-2 and of $62.5 \mu \mathrm{g} / \mathrm{mL}$ for QCG-3. In particular, the QCG-3 was able to inhibit the growth of $S$. aureus MR17 (MRSA), a methicillin-resistant clinical isolate from a surgical wound, at a concentration of $31.25 \mu \mathrm{g} / \mathrm{mL}$.

A close relationship between MIC and MBC values was observed (Table 2), which may indicate a bactericidal effect (Gonzalez et al., 2013). For instance, in the case of $S$. aureus (MRSA) ATCC 43300,
QCG-2 and QCG-3 presented the same value for MIC and MBC. The only trend of bacteriostatic effect occurred with S. epidermidis ATCC 12228 , for which the MIC of QCG-2 and QCG-3 was equal to $31.25 \mu \mathrm{g} / \mathrm{mL}$ and the MBC values for both derivatives was of $250 \mu \mathrm{g} / \mathrm{mL}$.

Through the analysis of Table 2 it is also visible that there is a consistent difference in the antimicrobial activity among the three QCG derivatives tested in this work, with respective MIC and MBC values decreasing in the following order: QCG-1 > QCG$2>$ QCG-3. To better visualize and understand this trend, Fig. 4 shows the relation between QCG chemical characteristics (Zeta potential and degree of substitution calculated by elemental analysis) and their antibacterial activity, which was represented by the mean of obtained MIC values for each derivative. It can be observed 


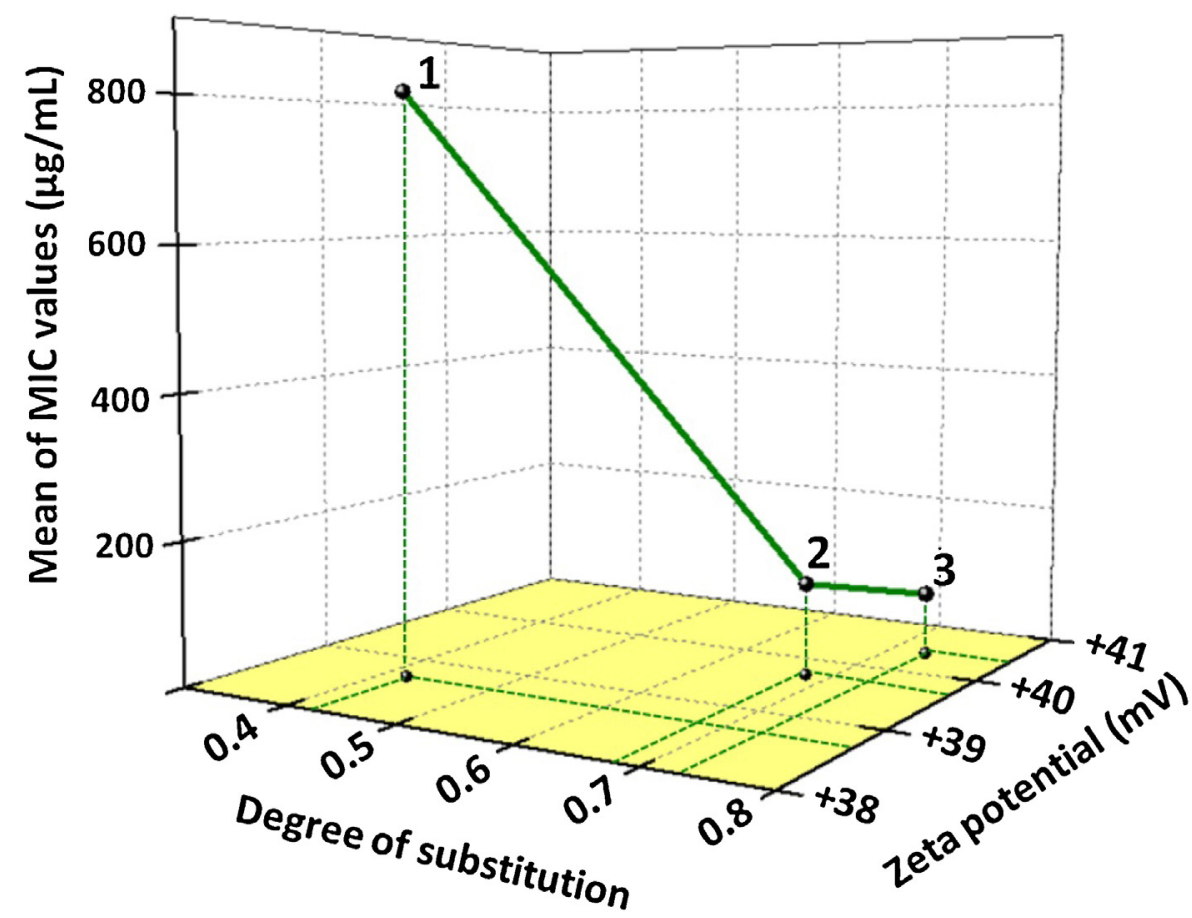

Fig. 4. Relation among chemical characteristics and antibacterial activity for each QCG derivative. 1: QCG-1, 2: QCG-2 and 3: QCG-3.

that the higher is the degree of substitution and Zeta potential values, the more potent was the QCG antimicrobial activity. Nichifor et al. (2010) also observed this behavior in one of the groups of quaternized dextran derivatives produced in their study.

An increased degree of substitution is related to the efficiency of the modification process carried out in the polymer chemical structure due to the inclusion of a quaternary ammonium substituent, which has, it self, well-known antibacterial activity (Ioannou, Hanlon, \& Denyer, 2007; Jennings et al., 2015). Concomitant with this, an increase in Zeta potential positive values was observed, due to incorporated positive charges in QCG. These effects can contribute to a stronger electrostatic interactions between the quaternized gums, which are polycations, and the negatively charged bacterial cell surface (Jennings et al., 2015; Tejero et al., 2015), enhancing the QCG damage to the Staphylococcus spp. membranes.

Contrary results were obtained by Sajomsang et al. (2009), who observed that the antimicrobial activity decreased with the increase in the quaternized chitosan degree of substitution. In contrast to the natural CG, chitosan has relevant antimicrobial activity, and its chemical modification, although improving its water solubility, could alter the interaction of the molecule with the bacterial surfaces.

Atomic force microscopy was used to analyze the effect of the most potent derivative (QCG-3) against S. aureus ATCC 29213 cells. In order to facilitate the analysis, MIC and MBC were determined against a higher number of cells (more concentrated inoculum), thus obtaining higher values, 500 and $1000 \mu \mathrm{g} / \mathrm{mL}$, respectively. This was found to be necessary, since very few cells were found in samples prepared with the standard inoculum.

Fig. 5A shows the non-treated bacteria forming the typical cluster of Staphylococcus spp., with a maximum height of $0.9 \mu \mathrm{m}$. Fig. $5 \mathrm{~B}$ and $C$ shows the MIC effect on $S$. aureus cells, with changes and a maximum height of the microorganisms around $1.4 \mu \mathrm{m}$. In Fig. 5D, in presence of the $\mathrm{MBC}$, alterations in size, volume and cell wall damage, with presence of roughness are clearly observed. These changes in bacterial size in relation to non-treated samples are statistically confirmed as shown in Fig. 5E.
The size increase may be also explained due to QCG-3 action on the cell membrane. Damages in this barrier may alter the cellular osmolarity causing water input from extracellular medium into the bacterium, as observed in S. aureus treated with antimicrobial plant extracts (Araújo, Quelemes et al., 2015). This disorder may be responsible for bacterial replication disability at MIC and its progression can be one of the probable causes that lead to death. A different result was obtained by Campos et al. (2012) that verified, also through AFM, that the pure CG $(10 \mathrm{mg} / \mathrm{mL})$ collapsed the $S$. aureus cells, probably because of the higher concentration used. The absence of total bacterial breakdown in cells due to the damage caused by the QCG-3, at the concentrations evaluated in this study, may be due to the rigidity of the peptidoglycan thick layer of Gram-positive cell wall (Eaton, Fernandes, Pereira, Pintado, \& Malcata, 2008).

\subsection{Biocompatibility assays}

Biocompatibility tests, for equivalent concentrations as used in the antimicrobial assays, were also performed for this study. The hemolysis assay measures the leakage of hemoglobin due damage of RBCs membranes. All QCG derivatives showed no hemolysis above $5 \%$, presenting excellent biocompatibility with RBCs even at the highest concentration tested (Fig. 6A). It was also observed a trend of greater hemolytic activity caused by the natural CG. Studies have reported the occurrence of decreasing hemolytic activity associated with a reduction in polymer hydrophobicity (Sahariah et al., 2015; Tejero, Loípez, Loípez-Fabal, Goímez-Garceís, \& FernaíndezGarcía, 2015).

To evaluate the cytotoxicity, the effect of CG and QCG derivatives on a keratinocyte cell line from adult human skin (HaCAT) and on a murine fibroblast line (NIH-3T3) were assessed. The selection of these cell lines for this test was based on the possible topical application of QCG, since the results were promising against skin pathogens. The results showed that in both cell lines, after direct action of all gums for $24 \mathrm{~h}$, the cell viability was maintained in more than 50\% (Fig. 6B and C). The keratinocytes viability after QCG-3 treatment, for instance, was around $70 \%$ even at the high concen- 


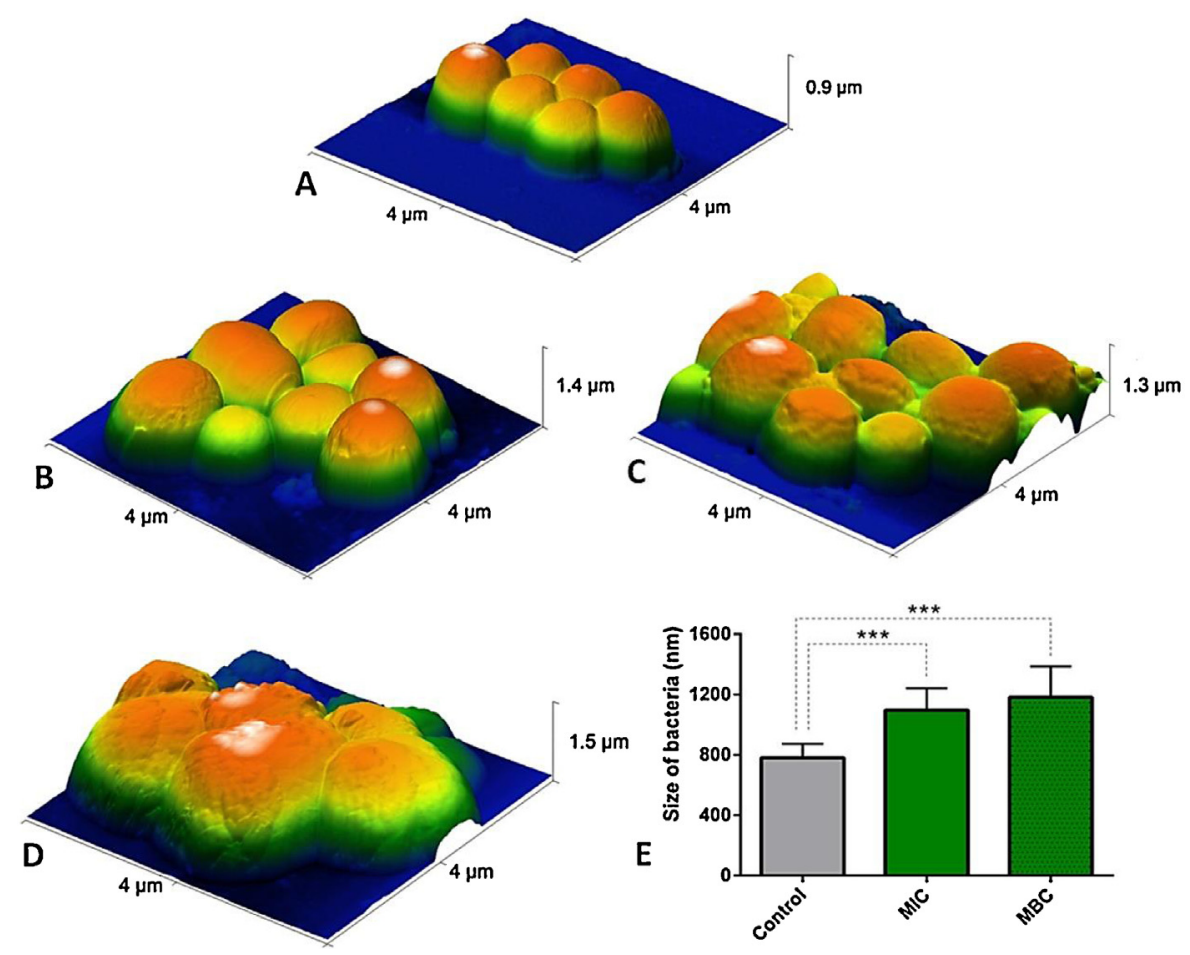

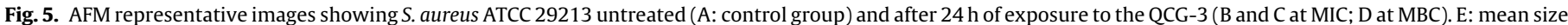

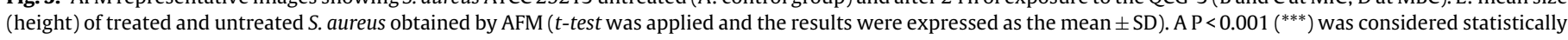
significant.
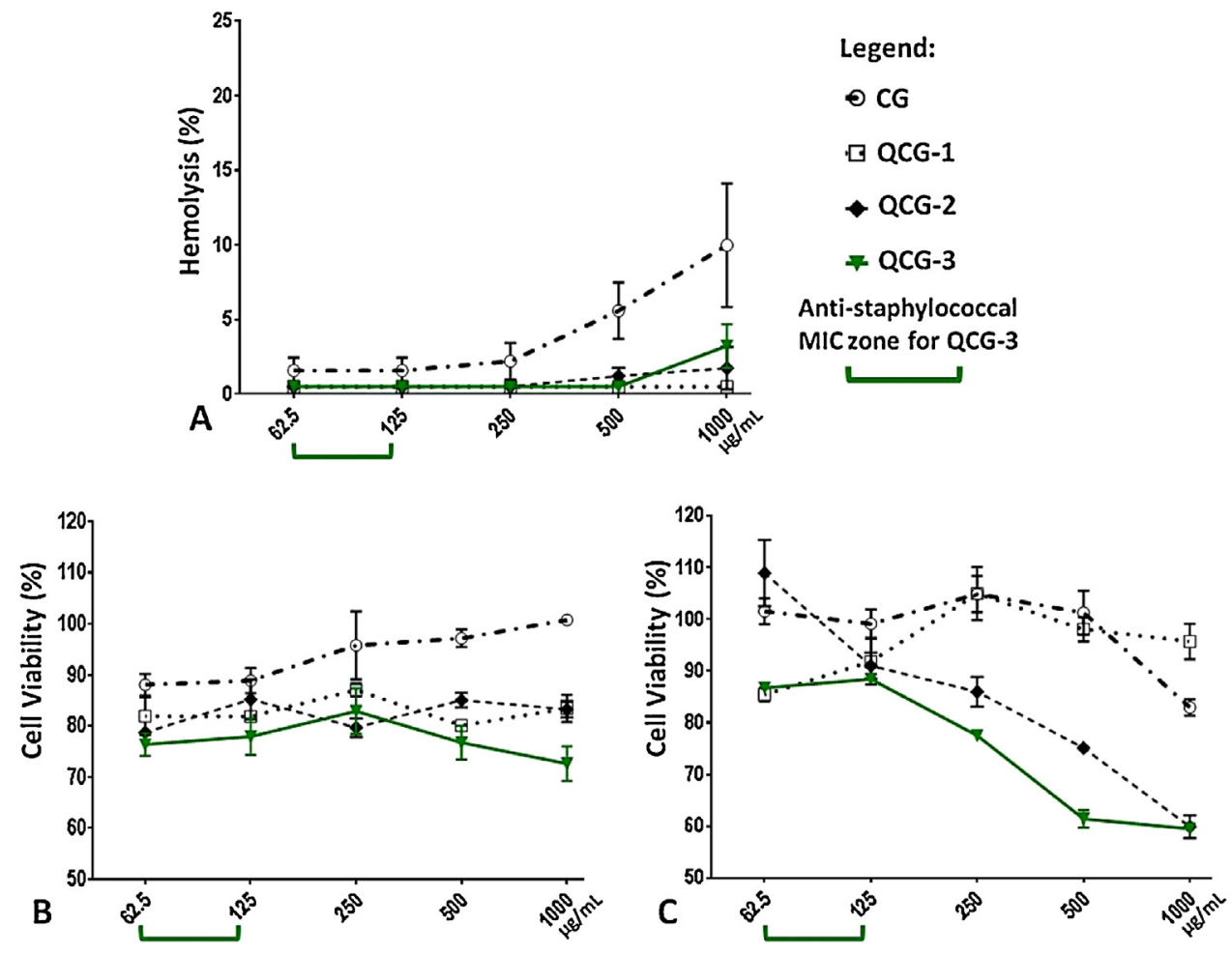

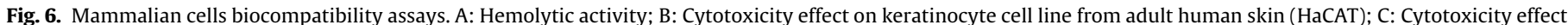
on murine fibroblast (NIH-3T3).

tration of $1000 \mu \mathrm{g} / \mathrm{mL}$ (Fig. 6B), which is about sixteen times higher than that which killed the S. aureus MRSA ATCC 43300. A decrease in fibroblast cell viability after the 24-h treatment with QCG-2 and QCG-3 at concentrations of 500 and $1000 \mu \mathrm{g} / \mathrm{mL}$ (Fig. 6C) was also noticed, however, those values were four to sixteen times greater than the MIC obtained for all Staphylococcus spp. tested.

Other studies have evaluated the cytotoxic effect of antiseptics commercially available on keratinocytes or fibroblasts (Damour 
et al., 1992; Hirsch et al., 2010; Muller and Kramer, 2008). Cytotoxic concentrations determined in vitro are sometimes considerably lower than concentrations of the respective antiseptics generally applied in clinical practice, therefore, it is considered that human tissue tolerates exposure to antiseptics better than tissue culture cells (Muller \& Kramer, 2008).

This work reports for the first time the direct biological effect of a chemical modified by insertion of new functional group CG. Even the least potent derivative, QCG-1 (MIC around $1000 \mu \mathrm{g} / \mathrm{mL}$ ), presented a marked increase in the anti-staphylococcal activity if compared with natural CG that has a MIC value of $30 \mathrm{mg} / \mathrm{mL}$ (Campos et al., 2012). Thus, there was a drastic improvement in the antimicrobial effect caused by quaternization process. Further studies are needed to better elucidate the QCG antimicrobial mechanism of action and a possible influence on the wound healing process. Biotechnological applications of modified gums are very common (Rana et al., 2011; Ribeiro et al., 2016), therefore, QCG can be very promising for the development of biomaterials when is intended some anti-septic effect.

\section{Conclusion}

A route for chemical modification of CG using a quaternary ammonium reagent has been presented. The chemical modification of the three derivatives proposed in this work was confirmed by thorough characterization. The hypothesis that the CG modification by quaternization process, with consequent acquisition of positive charges in its structure, could promote an enhancing of its antimicrobial effect was confirmed. Cationic QCG derivatives showed promising antibacterial effect against sensitive and resistant strains of Staphylococcus genus and its potency was related to the increasing degree of substitution and Zeta potential. QCG also showed biocompatibility on erythrocytes, keratinocytes and fibroblasts. Wherefore, the derivatives presented in this study present an opportunity for the development of QCG-based antistaphylococcal biomaterials and biotechnological devices.

\section{Acknowledgements}

Peter Eaton is supported by a Ciência sem Fronteiras grant via PVE- MEC/MCTI/CAPES/CNPQ/FAPS (Process Number 400398/2014-1), and his lab work is supported by financial support from FCT/MEC through national funds and co-financed by FEDER, under the partnership agreement PT2020. Alexandra Plácido is gratefully to FCT by her grant SFRH/BD/97995/2013, financed by POPH-QREN-Tipologia 4.1-Formação Avançada, subsidized by Fundo Social Europeu and Ministério da Ciência, Tecnologia e Ensino Superior. Peter Eaton is funded by FCT via grant UID/MULTI/04378/2013.

\section{References}

Araújo, T. S. L., Costa, D. S., Sousa, N. A., Souza, L. K. M., Araújo, S., Oliveira, A. P. et al. (2015). Antidiarrheal activity of cashew GUM, a complex heteropolysaccharide extracted from exudade of Anacardium occidentale L. in rodends. Journal of Ethnopharmacology, 174, 299-307.

Araújo, A. R., Quelemes, P. V., Perfeito, M. L. G., Lima, L. I., Sá, M. C., Nunes, P. H. M., et al. (2015). Antibacterial, antibiofilm and cytotoxic activities of Terminalia fagifolia Mart. extract and fractions. Annals of Clinical Microbiology and Antimicrobials, 14(25) http://dx.doi.org/10.1186/s12941-015-0084-2

Araruna, F. B., Quelemes, P. V., Faria, B. E. F., Kuckelhaus, S. A. S., Marangoni, V. S., Zucolotto, V., et al. (2013). Green synthesis and characterization of silver nanoparticles reduced and stabilized by cashew tree gum. Advanced Science, Engineering and Medicine, 5(8), 890-893.

Banerjee, C., Ghosh, S., Sen, G., Mishra, S., Shukla, P., \& Bandopadhyay, R. (2013). Study of algal biomass harvesting using cationic gum from the natural plant source as flocculant. Carbohydrate Polymers, 92, 675-681.

CLSI - Clinical Laboratory Standards Institute. (2012). Methods for dilution antimicrobial susceptibility test for bacteria that grow aerobically. Approved standard M02-A10. Pa: Wayne.
Campos, D. A., Ribeiro, A. C., Costa, E. M., Fernandes, J. C., Tavaria, F. K., Araruna, F. B., et al. (2012). Study of antimicrobial activity and atomic force microscopy imaging of the action mechanism of cashew tree gum. Carbohydrate Polymers, 90, 270-274.

Carvalho, N. S., Silva, M. M., Silva, R. O., Nicolau, L. A. D., Sousa, F. B. M., Damasceno, S. R. B., et al. (2015). Gastroprotective properties of cashew gum, a complex heteropolysaccharide of Anacardium occidentale, in naproxen-induced gastrointestinal damage in rats. Drug Development Research, 76(3), 143-151.

Cunha, P. L. R., Maciel, J. S., Sierakowski, M. R., de Paula, R. C. M., \& Feitosa, J. P. A. (2007). Oxidation of cashew tree gum exudate polysaccharide with TEMPO reagent. Journal of the Brazilian Chemical Society, 18, 85-92.

Cunha, P. L. R., Paula, R. C. M., \& Feitosa, J. P. A. (2009). Polysaccharides from Brazilian biodiversity: An opportunity to change knowledge into economic value. Química Nova, 32, 649-660.

Damour, O., Zhi Hua, S., Lasne, F., Villain, M., Rousselle, P., \& Collombel, C. (1992) Cytotoxicity evaluation of antiseptics and antibiotics on cultured human fibroblasts and keratinocytes. Bums, 18(6), 479-485.

De Paula, R. C. M., \& Rodrigues, J. F. (1995). Composition and rheological properties of cashew tree gum, the exudate polysaccharide from Anacardium occidentale L. Carbohydrate Polymers, 26(3), 177-181.

De Paula, R. C. M., Healthy, F., \& Budd, P. M. (1998). Characterization of Anacardium occidentale: Exudate polysaccharide. Polymer International, 45, 27-35.

DeLeo, F. R., \& Chambers, H. F. (2009). Reemergence of antibiotic-resistant Staphylococcus aureus in the genomics era. The Journal of Clinical Investigation, 119(9), 2464-2474.

Dias, S. F. L., Nogueira, S. S., Dourado, F. F., Guimarães, M. A., Pitombeira, N. A. O., Gobbo, G. G., et al. (2016). Acetylated cashew gum-based nanoparticles for transdermal delivery of diclofenac diethyl amine. Carbohydrate Polymers, 143, 254-261

Eaton, P., Fernandes, J. C., Pereira, E., Pintado, M. E., \& Malcata, F. X. (2008). Atomic force study of antibacterial effects of chitosans on Escherichia coli and Staphylococcus aureus. Ultramicroscopy, 108, 1128-1134.

Gonzalez, N., Sevillano, D., Alou, L., Cafini, F., Gimenez, M., Gomez-Lus, M. L., et al. (2013). Influence of the MBC/MIC ratio on the antibacterial activity of vancomycin versus linezolid against methicillin-resistant Staphylococcus aureus isolates in a pharmacodynamics model simulating serum and soft tissue interstitial fluid concentrations reported in diabetic patients. Journal of Antimicrobial Chemotherapy, 68(10), 2291-2295.

Gowthamarajan, K., Kumar, G. K. P., Gaikwad, N. B., \& Suresh, B. (2011). Preliminary study of Anacardium occidentale gum as binder in the formulation of paracetamol tablets. Carbohydrate Polymers, 83, 506-511.

Hirsch, T., Koerber, A., Jacobsen, F., Dissemond, J., Steinau, H., Gatermann, S., et al. (2010). Evaluation of toxic side effects of clinically used skin antiseptics in vitro. Journal of Surgical Research, 164, 344-350.

Huang, Y., Yu, H., \& Xiao, C. (2007). pH-sensitive cationic guar/poly (acrlylic acid) polyelectrolyte hydrogels: Swelling and in vitro drug release. Carbohydrate Polymers, 69, 774-783.

Ioannou, C. J., Hanlon, G. W., \& Denyer, S. P. (2007). Action of disinfectan quaternary ammonium compounds against Staphylococcus aureus. Antimicrobial Agentes and Chemotherapy, 51(1), 296-306.

Jennings, M. C., Minbiole, K. P. C., \& Wuest, W. M. (2015). Quaternary ammonium compounds: An antimicrobial mainstay and platform for innovation to address bacterial resistance. ACS Infectious Diseases, 1, 288-303.

Jevons, M. P. (1961). Celbenin-resistant staphylococci. British Medical Journal, 1, $124-125$.

Kumar, R., Patil, M. B., Patil, S. R., \& Paschapur, M. S. (2009). Evaluation of Anacardium occidentale gum as gelling agent in aceclofenac gel. International Journal of PharmTech Research, 1(3), 695-704.

Kumar, A., Moin, A., Shruthi, R., Ahmed, A., \& Shivakumar, H. G. (2012). Cashew gum: A versatile hydrophyllic polymer: A review. Current Drug Therapy, 7, $2-12$.

Lima, R. D. N., Lima, J. R., de Salis, C. R., \& Moreira, R. D. (2002). Cashew-tree (Anacardium occidentale L.) exudate gum: A novel bioligand tool. Biotechnology and Applied Biochemistry, 2016(35), 45-53.

Muller, G., \& Kramer, A. (2008). Biocompatibility index of antiseptic agents by parallel assessment of antimicrobial activity and cellular cytotoxicity. Journal of Antimicrobial Chemotherapy, 61, 1281-1287.

Neto, E. D., Maciel, J. D., Cunha, P. L. R., de Paula, R. C. M., \& Feitosa, J. P. A. (2011). Preparation and characterization of a chemically sulfated cashew gum polysaccharide. Journal of the Brazilian Chemical Society, 22, 1953-1960.

Nichifor, M., Stanciu, M. C., \& Simionescu, B. C. (2010). New cationic hydrophylic and amphiphilic polysaccharides synthesized by one pot procedure. Carbohydrate Polymers, 82, 965-975.

Novac, O., Lisa, G., Profire, L., Tuchilus, C., \& Popa, M. I. (2014). Antibacterial quaternized gellan gum based particles for controlled release of ciprofloxacin with potential dermal applications. Materials Science and Engineering C, 35, 291-299.

Oliveira, E. F., Paula, H. C. B., \& de Paula, R. C. M. (2014). Alginate/cashew gum nanoparticles for essential oil encapsulation. Colloids and Surfaces B: Biointerfaces, 113, 146-151.

Pal, S., Mal, D., \& Singh, R. P. (2007). Synthesis and characterization of cationic guar gum: A high performance flocculating agent. Journal of Applied Polymer Science, 105, 3240-3245.

Pal, S., Ghosh, S., Sen, G., Jha, U., \& Singh, R. P. (2009). Cationic tamarind kernel polysaccharide (Cat TKP): A novel polymeric flocculant for the treatment of 
textile industry wastewater. International Journal of Biological Macromolecules, 45, 518-523.

Pasberg-Gauhl, C. (2014). A need for new generation antibiotics against MRSA resistant bacteria. Drug Discovery Today: Technologies, 11, 109-116.

Piraino, F., \& Selimovic, S. (2015). A current view of functional biomaterials for wound care, molecular and cellular therapies. BioMed Research International, 2015, 10 pages.

Pitombeira, N. A. O., Veras Neto, J. G., Silva, D. A., Feitosa, J. P. A., Paula, H. C. B., \& de Paula, R. C. M. (2015). Self-assembled nanoparticles of acetyled cashew gum: Characterization and evaluation as potential drug carrier. Carbohydrate Polymers, 17, 610-615.

Porto, B. C., \& Cristianini, M. (2014). Evaluation of cashew tree gum (Anacardium occidentale L.) emulsifying properties. LWT - Food Science and Technology, 59, 1325-1331.

Quelemes, P. V., Araruna, F. B., de Faria, B. E. F., Kuckelhaus, S. A. S., Silva, D. A. Mendonça, R. Z., et al. (2013). Development and antibacterial activity of cashew gum-based silver nanoparticles. International Journal of Molecular Sciences, 14, 4969-4981.

Rana, V., Rai, P., Tiwary, A. K., Singh, R. S., Kennedy, J. F., \& Knill, C. J. (2011). Modified gums: Approaches and applications in drug delivery. Carbohydrate Polymers, 83, 1031-1047.

Ribeiro, A. J., Souza, F. R. L., Bezerra, J. M. N. A., Oliveira, C., Novotny, D., Soares, M. F. L., et al. (2016). Gums' based delivery systems: Review on cashew gum and its derivatives. Carbohydrate Polymers, 147, 188-200.

Sahariah, P., Benediktssdoíttir, B. E., Hjaílmarsdoíttir, M., Sigurjonsson, O. E. Sørensen, K. K., Thygesen, M. B., et al. (2015). Impact of chain length on antibacterial activity and hemocompatibility of quaternary $N$-Alkyl and $\mathrm{N}, \mathrm{N}$-dialkyl chitosan derivatives. Biomacromolecules, 16, 1449-1460.

Sajomsang, W., Gonil, P., \& Tantayanon, S. (2009). Antibacterial activity of quaternary ammonium chitosan containing mono or disaccharide moietes: Preparation and characterization. International Journal of Biological Macromolecules, 44, 419-427.

Schirato, G. V., Monteiro, F. M. F., Silva, F. O., Lima Filho, J. L., Leão, A. M. A. C., \& Porto, A. L. F. (2006). O polissacarídeo do Anacardium occidentale L. na fase inflamatória do processo cicatricial de lesões cutâneas. Ciência Rural, 36(1), 149-154.
Silva, D. A., de Paula, R. C. M., Feitosa, J. P. A., Brito, A. C. F., Maciel, J. S., \& Paula, H. C. B. (2004). Carboxymethylation of cashew tree exudates polysaccharide. Carbohydrate Polymers, 58, 163-171.

Silva, D. A., Feitosa, J. P. A., de Paula, H. C. B., \& Paula, R. C. M. (2009). Synthesis and characterization of cashew gum/acrylic acid nanoparticles. Materials Science and Engineering C, 29, 437-441.

Singh, R. P., Pal, S., \& Ali, S. A. (2014). Novel biodegradable polymeric flocculants based on cationic polysaccharides. Advanced Materials Letters, 5(1), 24-30.

Song, Y., Sun, Y., Zhang, X., Zhou, J., \& Zhang, L. (2008). Homogeneous quaternization of cellulose in $\mathrm{NaOH} / \mathrm{Urea}$ aqueous solutions as gene carriers. Biomacromolecules, 9, 2259-2264.

Tejero, R., Loípez, D., Loípez-Fabal, F., Goímez-Garceís, J. L., \& Fernaíndez-García, M. (2015). High Efficiency antimicrobial thiazolium and triazolium side-chain polymethacrylates obtained by controlled alkylation of the corresponding azole derivatives. Biomacromolecules, 16, 1844-1854.

Torquato, D. S., Ferreira, M. L., Sá, G. C., Brito, E. S., Pinto, G. A. S., \& Azevedo, E. H. F. (2004). Evaluation of antimicrobial activity of cashew tree gum. World Journal of Microbiology \&' Biotechnology, 20, 505-507.

Wang, Y., \& Xie, W. (2010). Synthesis of cationic starch with a high degree of substitution in an ionic liquid. Carbohydrate Polymers, 80, 1172-1177.

Yamassaki, F. T., Lenzi, R. M., Campestrini, L. H., Bovo, F., Seyfried, M., Soldera-Silva, A., et al. (2015). Effect of the native polysaccharide of cashew-nut tree gum exudate on murine peritoneal macrophage modulatory activities. Carbohydrate Polymers, 125, 241-248.

Yu, F., Liu, Y., Lv, J., Qi, X., Lu, C., Ding, Y., et al. (2015). Antimicrobial susceptibility, virulence determinant carriage and molecular characteristics of Staphylococcus aureus isolates associated with skin and soft tissue infections. Brazilian Journal of Infectious Diseases, 19(6), 614-622.

Yu, H., Huang, Y., Ying, H., \& Xiao, C. (2007). Preparation and characterization of quaternary ammonium derivative of konjac glucomannan. Carbohydred Polymers, 69, 29-40. 